\title{
Two Low Profile Unbalanced Fed Inverted L Elements on Square Conducting Plane for MIMO Applications
}

\author{
E. Rohadi ${ }^{1,2}$, M. Taguchi ${ }^{1}$ \\ ${ }^{1}$ Graduate School of Engineering, Nagasaki University, Nagasaki, Japan \\ ${ }^{2}$ The State Polytechnic of Malang, Malang, Indonesia \\ Email: bb52211281@cc.nagasaki-u.ac.jp, erfanr@polinema.ac.id, mtaguchi@nagasaki-u.ac.jp
}

Received 27 January 2014; revised 2 March 2014; accepted 19 March 2014

Copyright (C) 2014 by authors and Scientific Research Publishing Inc.

This work is licensed under the Creative Commons Attribution International License (CC BY). http://creativecommons.org/licenses/by/4.0/

(c) (i) Open Access

\begin{abstract}
Two ultra low profile inverted $L$ antennas located on the square conducting plane are numerically and experimentally analyzed as the multiple input multiple output (MIMO) antenna system. When the size of conducting plane is $0.45 \lambda$ by $0.45 \lambda$ and the height of antenna is $0.03 \lambda$, the directive gain of $4.12 \mathrm{dBi}$ and the return loss bandwidth of $3.67 \%$ are achieved. The proposed antenna has good diversity gain shown by the correlation coefficient, and becomes less than 0.02 at the frequency of $2.45 \mathrm{GHz}$ band when the distance between inverted L elements is $0.33 \lambda$. The results show the weak mutual coupling of the proposed antenna and its performances are promising as MIMO antenna applications.
\end{abstract}

\section{Keywords}

Low Profile Antenna, Inverted L Antenna, MIMO Antenna, Correlation Coefficient, WIPL-D

\section{Introduction}

The demand for high data rate and large channel capacity of users in recent mobile communication systems drives the MIMO systems as the subject of investigation for several years [1]. A practical MIMO antenna should have a low signal correlation between antenna elements and good impedance matching characteristics [2] [3]. The mutual coupling is an important factor when antennas have been used for MIMO applications [4] [5]. Higher mutual coupling may result in lower antenna efficiencies and higher correlation coefficients. The effect of mutual coupling on the capacity of MIMO wireless channel was studied in [6]. One of the most critical parameter affecting mutual coupling and correlation is the spacing between antenna elements. Analytical studies 
have shown that the distance between typical antenna elements such as dipole antenna needs to be at least half wavelengths for minimal or no mutual coupling [7]. However, since the distance is limited due to the small area which the elements are placed, especially at the portable MIMO-enabled devices, the MIMO antennas should be designed as small as possible. This is more conspicuous when MIMO antennas will be used in small terminal devices and more effort will be devoted to devising new MIMO antenna elements with compact and reasonable antenna characteristics [8]-[10]. The authors have proposed the unbalanced fed, ultra low profile inverted L antenna on a rectangular conducting plane for mobile terminal devices [11] [12]. When the size of conducting plane is $0.245 \lambda$ ( $\lambda$ : wavelength) by $0.49 \lambda$ and the antenna height is $\lambda / 30$, and the length of horizontal element is around a quarter wavelength, the input impedance of this antenna is matched to $50 \Omega$ and its directivity becomes more than $4 \mathrm{dBi}$. In this antenna, the electromagnetic field is strongly excited between the inverted L element and the conducting plane. Therefore even though two inverted L antennas are closely located, the mutual coupling may be weak.

Several other designs of MIMO antenna satisfy for the requirement of MIMO systems; unfortunately these antennas have limitation of size for practical MIMO application. Also in general, MIMO antennas consist of complicated structures [13]-[18]. For example, in [17], two meandered monopoles with a gamma matching and a folded T-shaped stub between radiators are printed on an FR4 substrate with its size of $30 \mathrm{~mm}$ by $15 \mathrm{~mm}$. Its directivity is less than $0 \mathrm{dBi}$. In this paper, the very simple antenna composed of two unbalanced fed, ultra low profile inverted $\mathrm{L}$ antennas on a square conducting plane with its size of $55 \mathrm{~mm}$ is proposed as MIMO antenna applications [19]. In the numerical analysis, the electromagnetic simulator WIPL-D based on the Method of Moments is used [20].

\section{Antenna Structure}

Figure 1 shows the structure of the proposed antenna. Two identical low profile inverted $\mathrm{L}$ antenna elements with the height $h=4 \mathrm{~mm}$ are mounted on the square conducting plane with its size of $55 \mathrm{~mm}$ by $55 \mathrm{~mm}$. The antenna size corresponds to $0.45 \lambda$ by $0.45 \lambda$ by $0.03 \lambda$ at the design frequency of $2.45 \mathrm{GHz}$. The antenna elements are composed of the semi rigid coaxial cable with outer and inner radius $1.095 \mathrm{~mm}$ and $0.255 \mathrm{~mm}$, respectively. The inner conductor of the coaxial cable is extended from the end of outer conductor, that is, each antenna element is excited at the end of outer conductor. The distance $d$ between two antenna elements are investigated in order to reduce the mutual coupling. Furthermore the distance is challenged to be less than half wavelength. Both the distance pym between the vertical element to the back edge of the ground plane and distance pyp between the vertical element to the front edge are fixed as $10 \mathrm{~mm}$ and $45 \mathrm{~mm}$, respectively. In each case of the distance between two antennas, the length of horizontal elements $L$ and $L 1$ are optimized to achieve impedance matching at the center frequency of $2.45 \mathrm{GHz}$. Figure 2 shows other arrangements of antenna elements.

\section{Results and Discussion}

In the calculation, the distance $d$ between two inverted $\mathrm{L}$ antennas is changed from $30 \mathrm{~mm}$ to $45 \mathrm{~mm}$. Table 1 shows the calculated return loss bandwidth larger than $10 \mathrm{~dB}$, S21 and the directive gain in the z direction at $2.45 \mathrm{GHz}$ for the different distance $d$ between two inverted L elements. Figure 3 shows calculated S parameters of the optimized proposed MIMO antenna arrangement- 1 for different distance $d$ between two antenna elements. S21 becomes smaller than $-20 \mathrm{~dB}$ as the distance $\mathrm{d}$ become longer than $41 \mathrm{~mm}$.

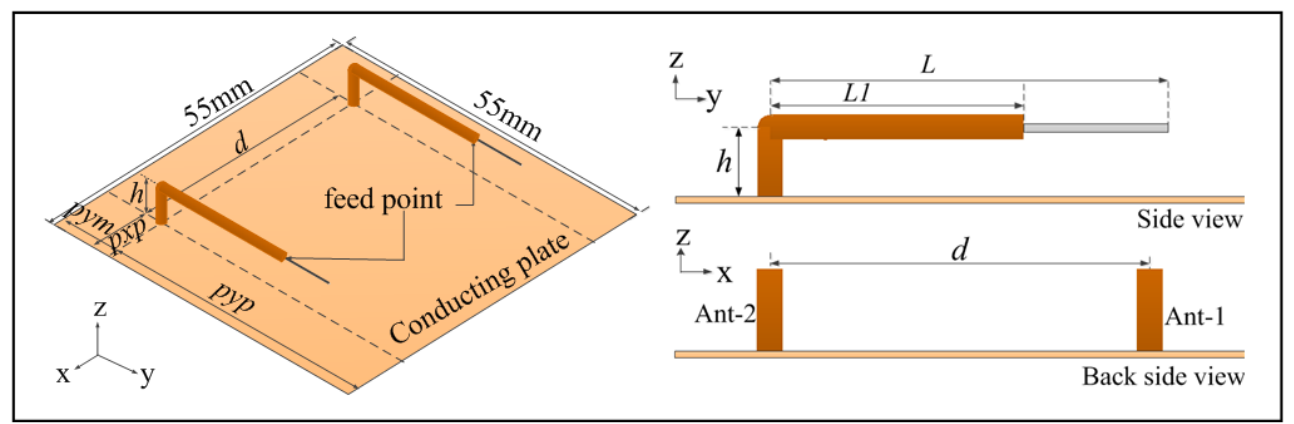

Figure 1. The structure of proposed antenna; arrangement-1 (pym $=10 \mathrm{~mm}$, pyp $=45 \mathrm{~mm}, h=4 \mathrm{~mm})$. 


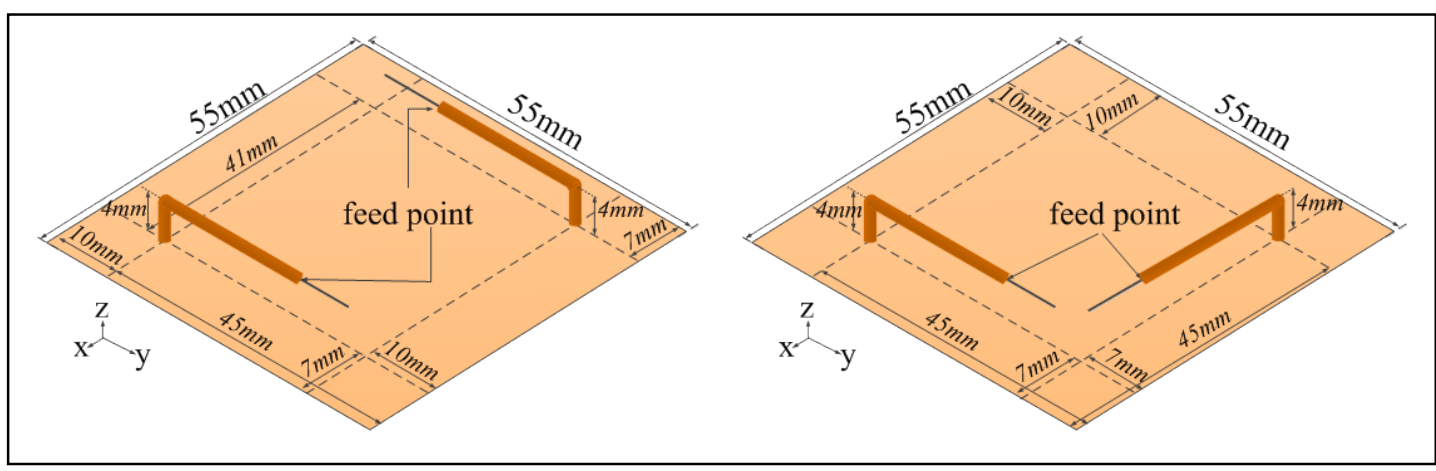

(a)

(b)

Figure 2. (a) Arangement-2; opposite parallel and (b) arrangement-3; face to face perpendicular arrangements.

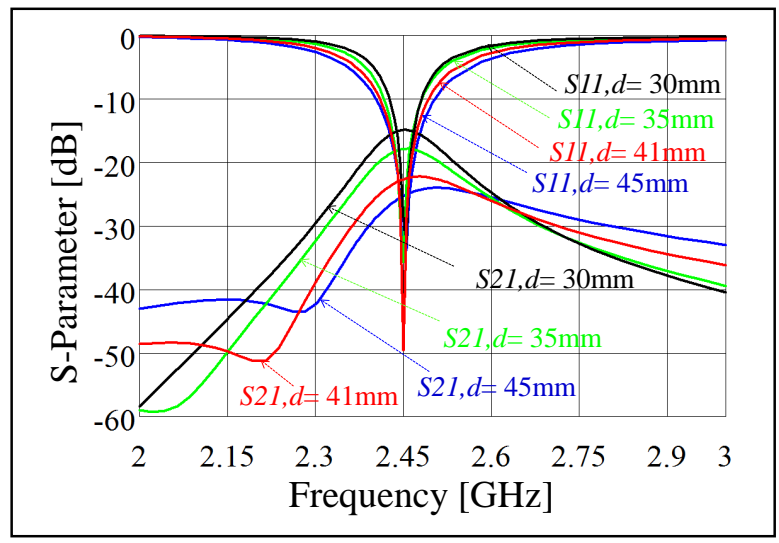

Figure 3. Calculated $\mathrm{S}$ parameters of proposed antenna for different $d$ (arrangement-1, $h=4 \mathrm{~mm}$, pym $=10 \mathrm{~mm}$, pyp = $45 \mathrm{~mm})$.

Table 1. Calculated return loss bandwidth, S21 and directivity for different distance between two antennas $d$ (arrangement-1).

\begin{tabular}{|c|c|c|c|c|c|c|}
\hline \multirow{2}{*}{\multicolumn{3}{|c|}{$\begin{array}{c}h=4 \mathrm{~mm}, \text { pym }=10 \mathrm{~mm} \\
\text { pyp }=45 \mathrm{~mm} \\
{[\mathrm{~mm}]}\end{array}$}} & \multirow{2}{*}{\multicolumn{2}{|c|}{$\begin{array}{l}\text { Return loss } \\
\text { bandwidth }\end{array}$}} & \multirow{3}{*}{$\begin{array}{c}\text { S21 at } 2.45 \\
\quad \mathrm{GHz} \\
{[\mathrm{dB}]}\end{array}$} & \multirow{3}{*}{$\begin{array}{c}\text { Dir. Gain at } \\
2.45 \mathrm{GHz} \\
\text { [dBi] }\end{array}$} \\
\hline & & & & & & \\
\hline$d / p x p$ & $L$ & $L 1$ & {$[\mathrm{MHz}]$} & [\%] & & \\
\hline $30 / 12.5$ & 30.7 & 22.7 & 50 & 2.04 & -14.83 & 3.79 \\
\hline $35 / 10$ & 30.9 & 22.2 & 60 & 2.45 & -17.86 & 3.98 \\
\hline $41 / 7$ & 31.2 & 21.4 & 90 & 3.67 & -22.64 & 4.12 \\
\hline $45 / 5$ & 31.4 & 20.7 & 100 & 4.08 & -25.28 & 4.17 \\
\hline
\end{tabular}

Table 2 shows the calculated return loss bandwidth, S21 and the directive gain in the z direction at $2.45 \mathrm{GHz}$ for different antenna height $h$. When the height of antenna is increased, both the length of horizontal elements $L$ and $L 1$ become shorter. This means that the resonant frequency is determined by the total length of horizontal and vertical elements. Figure 4 shows calculated S parameters of the proposed MIMO antenna arrangement-1 for different antenna height $h$. The return loss bandwidth and S21 become smaller as the antenna height $h$ becomes smaller. As the antenna height becomes smaller, the electromagnetic field concentrates near the excited antenna element. Therefore the return loss bandwidth becomes narrower and the mutual coupling between two antennas becomes weak. 
Table 2. Calculated return loss bandwidth and directivity for different antenna height $h$ (arrangement-1).

\begin{tabular}{ccccccc}
\hline$d=41 \mathrm{~mm}$, pym $=10 \mathrm{~mm}$, pyp $=45 \mathrm{~mm}$, pxp $=7 \mathrm{~mm}$ & $\begin{array}{c}\text { Return loss } \\
\text { bandwidth }\end{array}$ & $\begin{array}{c}\text { S21 at } \\
2.45 \mathrm{GHz}\end{array}$ & $\begin{array}{c}\text { Dir. Gain at } \\
2.45 \mathrm{GHz}\end{array}$ \\
\hline$h$ & $L$ & $L 1$ & $\mathrm{MHz}$ & {$[\%]$} & {$[\mathrm{dB}]$} & {$[\mathrm{dBi}]$} \\
3 & 31.9 & 23.9 & 50 & 2.04 & -24.06 & 4.09 \\
4 & 31.2 & 21.4 & 90 & 3.67 & -22.64 & 4.12 \\
5 & 30.6 & 19.1 & 120 & 4.90 & -21.67 & 4.08 \\
6 & 29.9 & 16.8 & 140 & 5.71 & -20.98 & 4.05 \\
\hline
\end{tabular}

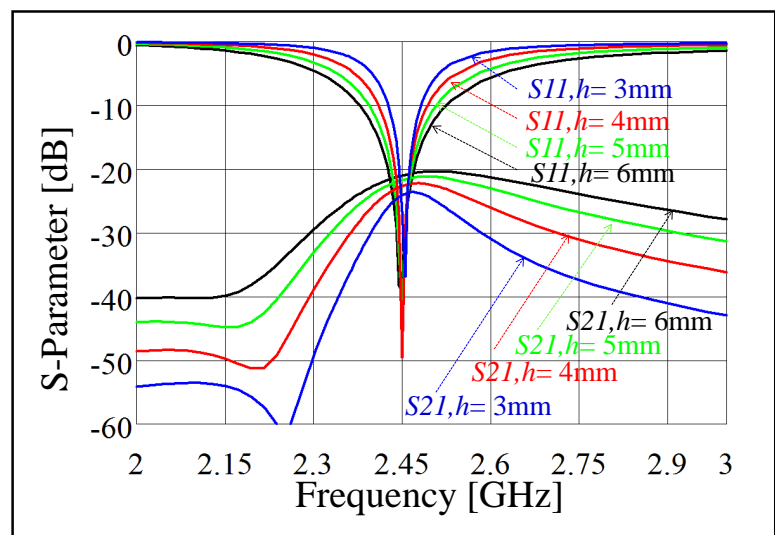

Figure 4. Calculated S parameters of proposed antenna for different $h$ (arrangement-1, $d=41 \mathrm{~mm}$, pxp $=7 \mathrm{~mm}$, pym $=$ $10 \mathrm{~mm}$, pyp $=45 \mathrm{~mm})$.

Figure 5 shows the return loss bandwidth larger than $10 \mathrm{~dB}$ and the directive gain in the $\mathrm{z}$ direction at 2.45 GHz of the proposed MIMO antenna arrangement-1 for different distance $d$ between two antenna elements and for different height $h$ of antenna. Both the directive gain and the return loss bandwidth become larger by extending the distance between two antennas.

Figure 6 shows the directive gain in the $\mathrm{z}$ direction at the proposed MIMO antenna arrangement-1. Figure 7 shows the current distribution of proposed MIMO antenna arrangement-1 at $2.45 \mathrm{GHz}$. The inverted L element- 1 is excited and the element- 2 is terminated with $50 \Omega$ load. The large surface current is induced near inverted $L$ element-1, on the other hand weak surface current is induced on the element- 2 at resonant frequency of $2.45 \mathrm{GHz}$. This means that the good isolation between two elements is achieved.

Figure 8 shows the electric field radiation patterns on zx plane, yz plane and xy plane of the proposed MIMO antenna arrangement- 1 at $2.45 \mathrm{GHz}$ when inverted L element- 1 is fed and inverted L element- 2 is terminated by the matching load $50 \Omega$. The peak gain of antenna- 1 is $4.12 \mathrm{dBi}$. The current distribution on the inverted $\mathrm{L}$ antennas in the $\mathrm{y}$ direction and the surface on the conducting plane in the $\mathrm{x}$ and $\mathrm{y}$ directions contribute to the radiation. Therefore there are no deep nulls in any direction, although omnidirectional polarization antennas are used in general.

Figure 9 shows the near field distributions in the zx plane including feed points of arrangement-1, in the zx plane including the feed point of element1 of arrangement-2, and in the yz plane including feed point of element-2 of arrangement-3 at $2.45 \mathrm{GHz}$.

Figure 10 shows the near field distributions in xy plane including horizontal elements of each arrangement at $2.45 \mathrm{GHz}$. The good isolation is achieved in the balanced structure as proposed MIMO arrangent- 1 . Whereas, it can be seen that two elements are highly coupled to each other at arrangement- 2 and arrangement- 3 .

From Figure 7, Figure 9 and Figure 10, in the case of proposed MIMO antenna arrangement-1, the surface current on the conducting plane between two antennas is small and the electromagnetic field becomes weak near 

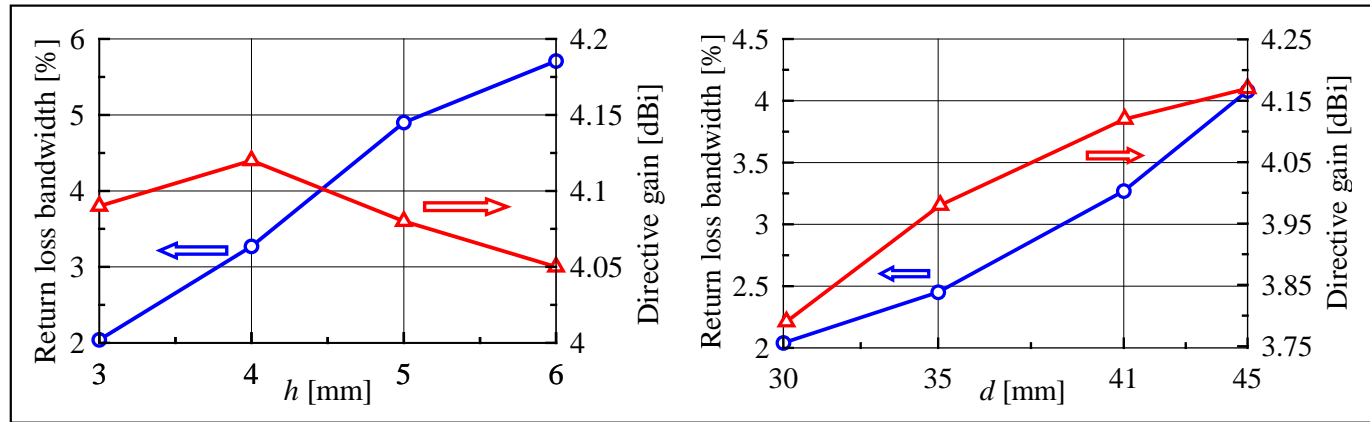

Figure 5. Return loss bandwidth and directive gain in z direction at $2.45 \mathrm{GHz}$ (arrangement-1; $p x p=7 \mathrm{~mm}$, pym $=10 \mathrm{~mm}$, pyp $=45 \mathrm{~mm})$.

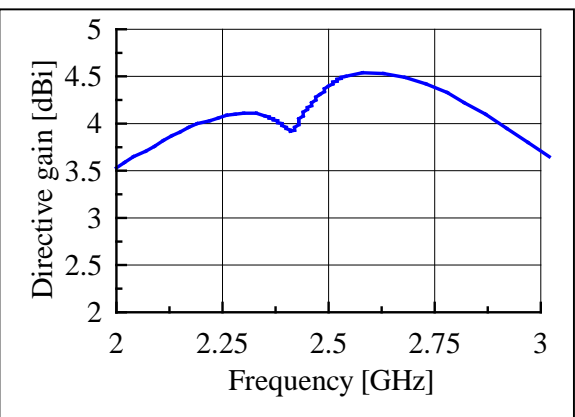

Figure 6. Calculated directive gain at $\mathrm{z}$ direction (arrangemet- $1 ; p x p=7 \mathrm{~mm}$, pym $=10$ $\mathrm{mm}$, pyp $=45 \mathrm{~mm}, h=4 \mathrm{~mm}, d=41 \mathrm{~mm})$.

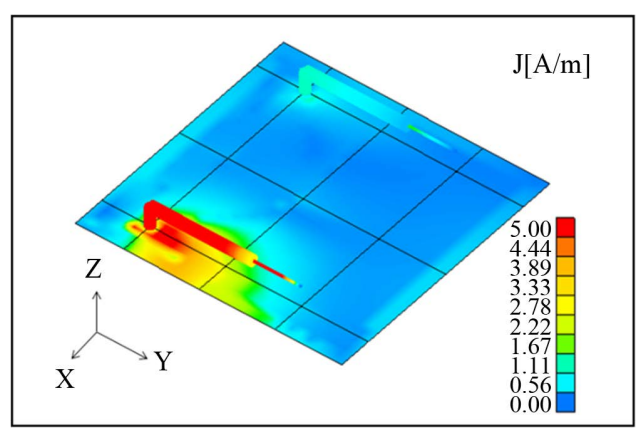

Figure 7. Calculated current distribution at frequency of $2.45 \mathrm{GHz}$ (arrangement- $1 ; h=4 \mathrm{~mm}$, $d=41 \mathrm{~mm}$, pxp $=7 \mathrm{~mm}$, pym $=10 \mathrm{~mm}$, pyp $=45$ $\mathrm{mm}, L=31.2 \mathrm{~mm}, L 1=21.4 \mathrm{~mm})$.

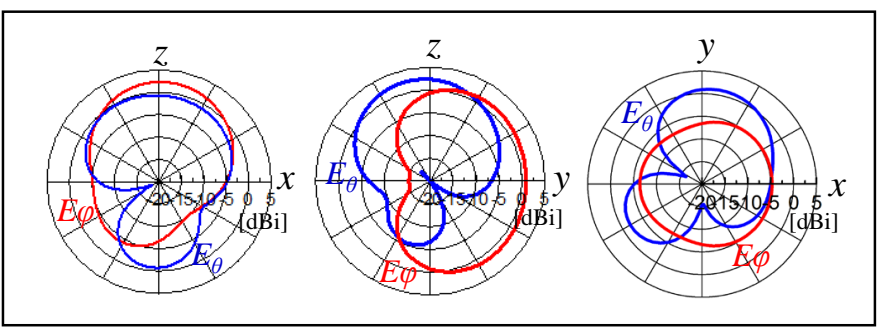

Figure 8. Simulated electric field radiation pattern of proposed antenna at $2.45 \mathrm{GHz}$ (arrangement-1; $h=4 \mathrm{~mm}, \mathrm{~d}=41 \mathrm{~mm}$, $p x p=7$ $\mathrm{mm}$, pym $=10 \mathrm{~mm}$, pyp $=45 \mathrm{~mm}, L=31.2 \mathrm{~mm}, L 1=21.4 \mathrm{~mm})$. 


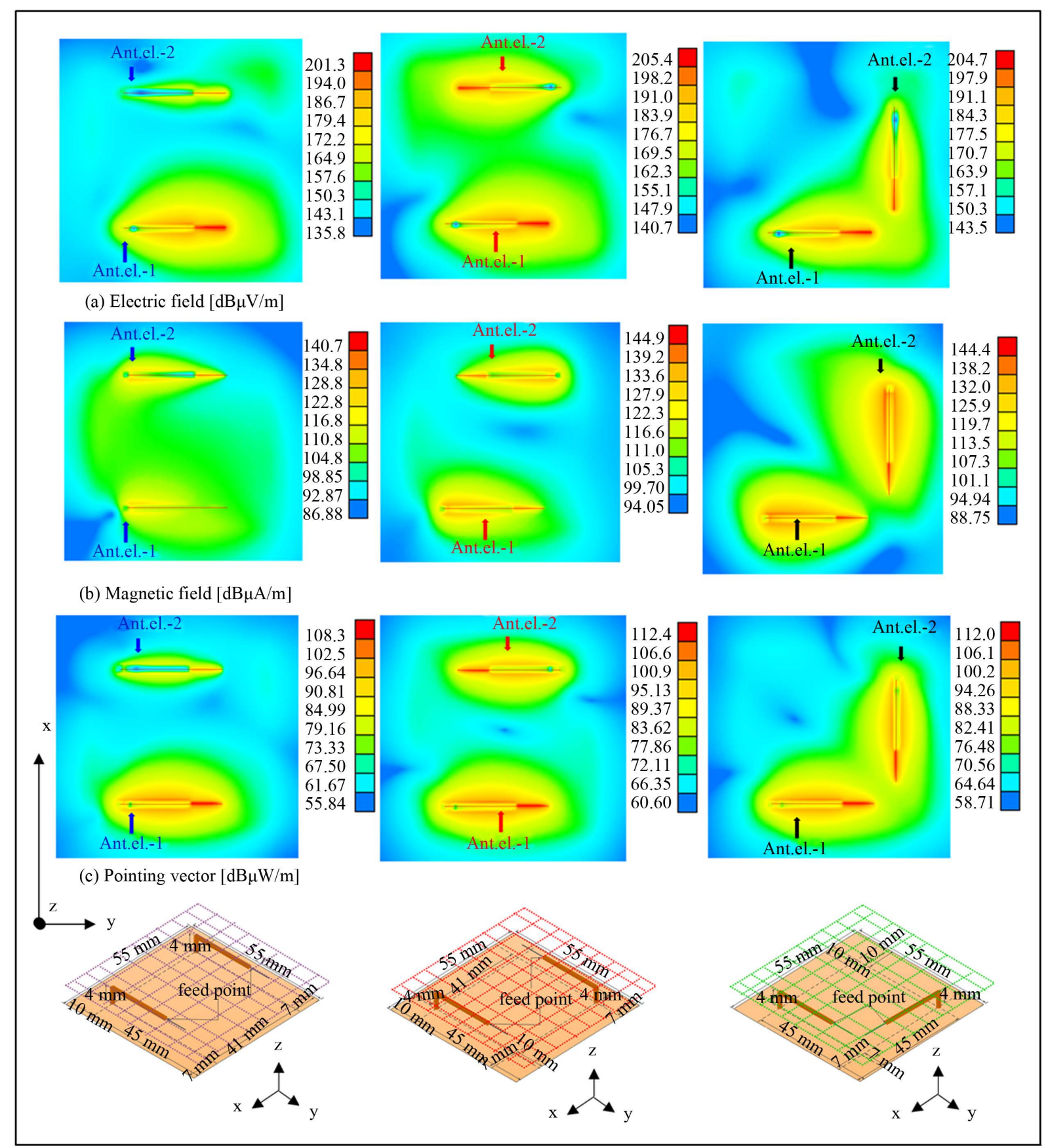

Figure 9. The near field distribution at $2.45 \mathrm{GHz}(h=4 \mathrm{~mm}, \mathrm{~d}=41 \mathrm{~mm}, p x p=7 \mathrm{~mm}$, pym $=10 \mathrm{~mm}$, pyp $=45 \mathrm{~mm}, L=31.2$ $\mathrm{mm}, L 1=21.4 \mathrm{~mm})$.

the conducting plane between two antennas. This means that the mutual coupling is mainly not by the current flowing on the conducting plane but by the spatial coupling.

Figure 11 shows the reflection coefficients of three arrangements. The placement of inverted L elements as arrangement 1 obtains the best isolation between two elements.

Figure 12 shows the calculated and measured S parameters of proposed MIMO arrangement-1. The fairly good agreement between calculated and measured results is obtained.

The correlation coefficient of the proposed MIMO antenna is calculated through S parameter. The correlation coefficient $\rho_{e}$ of a two element inverted L antenna system can be calculated by the following equation [21]; 


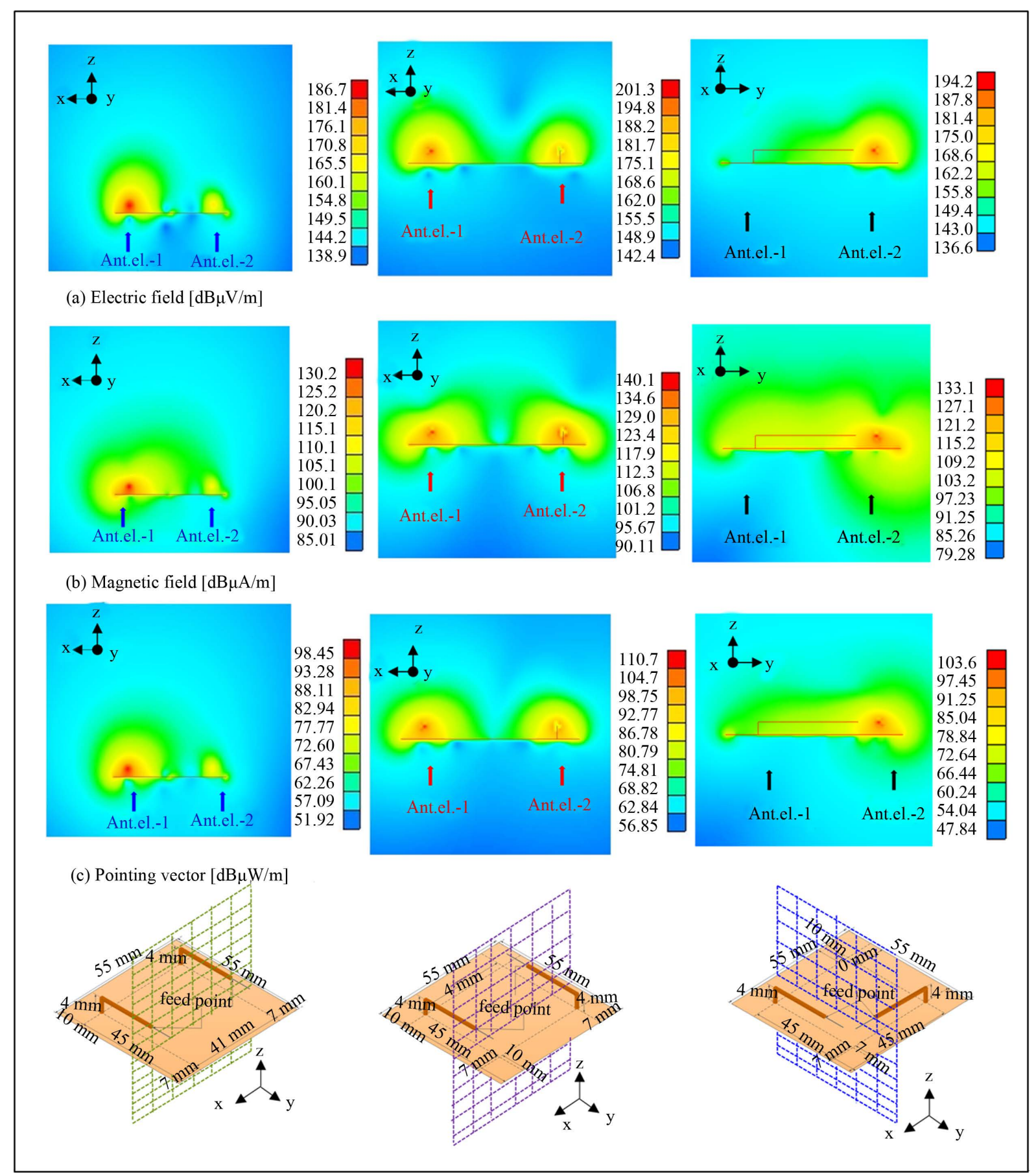

Figure 10. The near field distribution on horizontal elements of xy plane at $2.45 \mathrm{GHz}(h=4 \mathrm{~mm}, \mathrm{~d}=41 \mathrm{~mm}, p x p=7 \mathrm{~mm}$, pym $=10 \mathrm{~mm}$, pyp $=45 \mathrm{~mm}, L=31.2 \mathrm{~mm}, L 1=21.4 \mathrm{~mm})$.

$$
\rho_{e}=\frac{\left|S_{11} * S_{12}+S_{21} * S_{22}\right|^{2}}{\left(1-\left(\left|S_{11}\right|^{2}+\left|S_{21}\right|^{2}\right)\right)\left(1-\left(\left|S_{22}\right|^{2}+\left|S_{12}\right|^{2}\right)\right)}
$$

Figure 13 shows calculated and measured correlation coefficient of the proposed MIMO antenna arrangement-1. The correlation coefficient becomes less than 0.02 , which means that the proposed antenna has good 


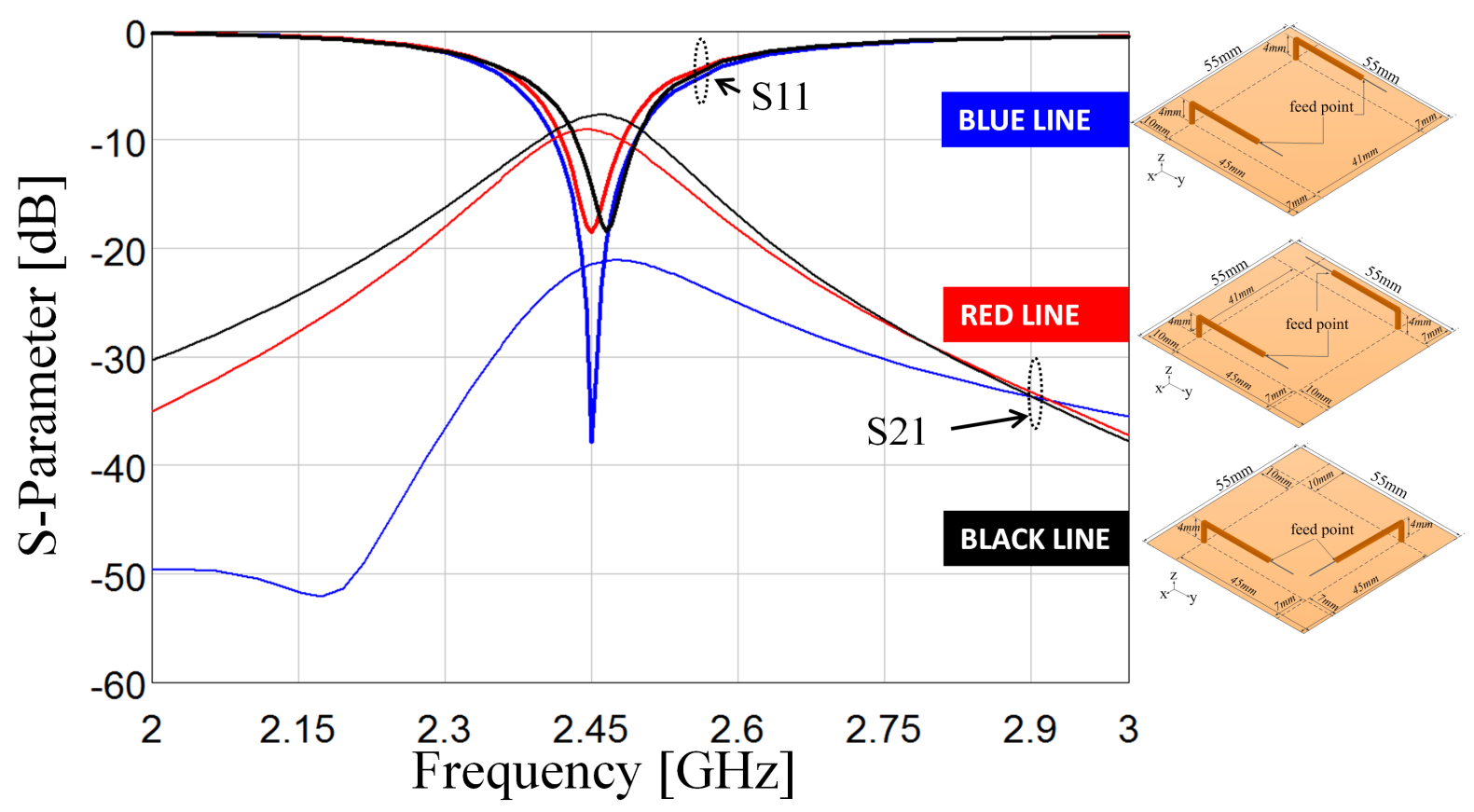

Figure 11. Reflection coefficients of proposed antenna with different arrangements $(h=4 \mathrm{~mm}, \mathrm{~d}=41 \mathrm{~mm}, p x p=7 \mathrm{~mm}$, pym $=10 \mathrm{~mm}$, pyp $=45 \mathrm{~mm}, L=31.2 \mathrm{~mm}, L 1=21.4 \mathrm{~mm})$.

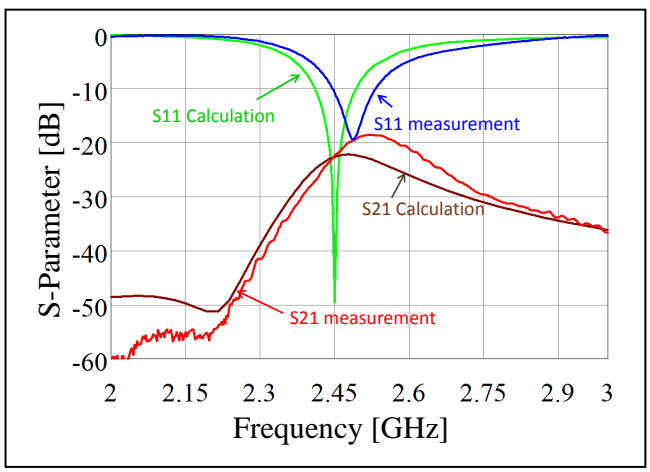

Figure 12. Calculated and measured $S$ parameters of the proposed MIMO antenna ( $p x p=7 \mathrm{~mm}$, pym $=10 \mathrm{~mm}$, pyp $=45 \mathrm{~mm}, h=4 \mathrm{~mm}, d=41 \mathrm{~mm}$ ).

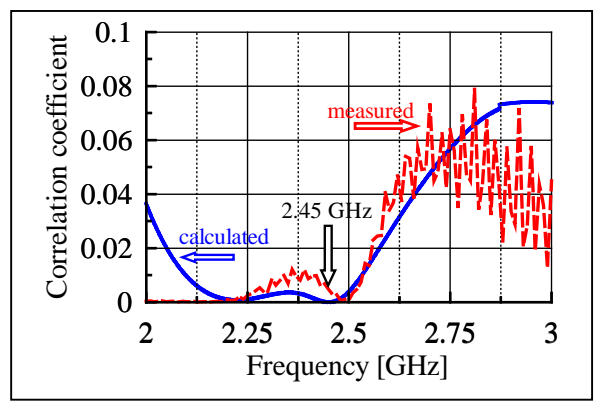

Figure 13. Calculated and measured correlation coefficient between two inverted $\mathrm{L}$ antennas (arrangemet-1; pxp $=7 \mathrm{~mm}$, pym $=10$ $\mathrm{mm}$, pyp $=45 \mathrm{~mm}, h=4 \mathrm{~mm}, d=41 \mathrm{~mm})$. 
diversity gain when antenna height and the distance between inverted L elements are $4 \mathrm{~mm}$ and $41 \mathrm{~mm}$, respectively.

\section{Conclusion}

The MIMO antenna, composed of two unbalanced fed, ultra low profile inverted L antenna elements, has been proposed. Two inverted L elements are parallel located on the square conducting plane with its size of $045 \lambda$ by $0.45 \lambda$. The height of inverted $L$ antennas is $0.03 \lambda$, and the distance between two inverted $L$ antennas is $0.34 \lambda$. With a very simple structure, the antenna has the good performances. The calculated and measured return loss larger than $10 \mathrm{~dB}$ is 2.41 to $2.50 \mathrm{GHz}$ and 2.44 to $2.53 \mathrm{GHz}$, respectively. The directive gain is $4.12 \mathrm{dBi}$. The proposed antenna is promising for MIMO application systems.

\section{Acknowledgements}

Erfan Rohadi would like to thank to the General of Higher Education, Ministry Education and Culture of Republic Indonesia for providing the scholarship of the doctoral course program.

\section{References}

[1] Yu, X.H., Wang, L., Wang, H.G., Wu, X.D. and Shang, Y.H. (2012) A Novel Multiport Matching Method for Maximum Capacity of an Indoor MIMO System. Progress in Electromagnetics Research, 130, 67-34. http://dx.doi.org/10.2528/PIER12040603

[2] Ding, Y., Du, Z., Gong, K. and Feng, Z. (2007) A Novel Dula-Band Printed Diversity Antenna for Mobile Terminal. IEEE Transactions on Antennas and Propagations, 55, 2088-2096. http://dx.doi.org/10.1109/TAP.2007.900249

[3] Costa, J.R., Lima, E.B., Medeiros, C.R. and Fernandes, C.A. (2011) Evaluation of a New Wideband Slot Array for MIMO Performance Enhancement in Indoor WLANs. IEEE Transactions on Antennas and Propagations, 59, 12001206. http://dx.doi.org/10.1109/TAP.2011.2109685

[4] Karimian, R., Soleimani, M. and Hashemi, S.M. (2012) Tri-Band four Elements MIMO Antenna System for WLAN and WIMAX Application. Journal of Electromagnetic Waves and Applications, 26, 2348-2357. http://dx.doi.org/10.1080/09205071.2012.734433

[5] Cui, S., Gong, S.X., Liu, Y. and Guan, Y. (2011) Compact and Low Coupled Monopole Antennas for MIMO Systems Applications. Journal of Electromagnetic Waves and Applications, 25, 703-712. http://dx.doi.org/10.1163/156939311794827221

[6] Abouda, A.A. and Hagman, S.G. (2006) Effect on Mutual Coupling Capacity on MIMO Wireless Channels in High SNR Scenario. Progress in Electromagnetics Research Symposium, 65, 27-40.

[7] Stutzman, W.L. and Thiele, G.A. (1998) Antenna Theory and Design. 2nd Edition, Wiley, New York, 154-160.

[8] Foschini G.J. and Gans, M.J. (1998) On Limits of Wireless Communications in Fading Environment When Using Multiple Antennas. Wireless Personal Communications, 6, 311-335. http://dx.doi.org/10.1023/A:1008889222784

[9] Fujimoto, K., Henderson, A., Hirasawa, K. and James, J.R. (1987) Small Antennas. Research Studies Press, Letchworth, 116-151.

[10] Hirasawa, K. and Haneishi, M. (1992) Analysis, Design, and Measurement of Small and Low-Profile Antennas. Artech House Inc., Norwood, 165-169.

[11] Yamashita, T. and Taguchi, M. (2009) Ultra Low Profile Inverted L Antenna on a Finite Conducting Plane. International Sympoisum on Antennas and Propagation, Bangkok, 20-23 October 2009, 361-364.

[12] Rohadi, E. and Taguchi, M. (2012) Ultra Low Profile Antenna for 2.45 GHz Wireless Communications. IEEE International Conference on Communication, Networks and Satellite (ComNetSat), Bali, 12-14 July 2012, 103-107.

[13] Votis, C., Tatis, G. and Kostarakis, P. (2010) Envelope Correlation Parameter Measurements in a MIMO Antenna Array Configuration. International Journal of Communications, Network and System Sciences, 3, 350-354. http://dx.doi.org/10.4236/ijcns.2010.34044

[14] Ahn, S.B. and Choo, H.S. (2013) Design of Vehicle of On-Glass $4 \times 4$ MIMO Antennas for WIBRO Applications. International Journal of Automotive Technology, 14, 731-737.

[15] Zeng, Q., Yao, Y., Liu, S., Yu, J. and Chen, X. (2012) Tetraband Small-Size Printed Strip MIMO Antenna for Mobile Handset Application. International Journal of Antennas and Propagation, 2012, 320582. http://dx.doi.org/10.1155/2012/320582

[16] Lee, J.N, Lee, K.C., Park, N.H. and Park, J.K. (2013) Design of Dual-Band MIMO Antenna with High Isolation for 
Mobile Terminal. ETRI Journal, 35, 177-187. http://dx.doi.org/10.4218/etrij.13.0112.0250

[17] Jin, Z., Lim, J.H. and Yun, T.Y. (2012) Small-Size and High-Isolation MIMO Antenna for WLAN. ETRI Journal, 34, 114-117. http://dx.doi.org/10.4218/etrij.12.0211.0083

[18] Kim, S.H., Jin, Z.J., Chae, Y.B. and Yun, T.Y. (2013) Small Antenna Using Multiband, Wideband and High-Isolation MIMO Techniques. ETRI Journal, 35, 51-57. http://dx.doi.org/10.4218/etrij.13.0112.0183

[19] Rohadi, E. and Taguchi, M. (2013) Two Element Ultra Low Profile Inverted L Antennas on Finite Conducting Plate for MIMO Applications. International Conference on Advanced Technologies for Communications (ATC), Ho Chi Minh City, 16-18 October 2013, 74-77.

[20] WIPL-D d.o.o. (2013) WIPL-D Pro v11.0. http://www.wipl-d.com

[21] Thaysen, J. and Jakobsen, K.B. (2006) Envelope Correlation in (N,N) MIMO Antenna Array from Scattering Parameters. Microwave and Optical Technology Letters, 48, 832-834. http://dx.doi.org/10.1002/mop.21490 